\title{
Publicidade, Relações Públicas e algumas apropriações discursivas. O caso do Banco Itaú
}

\section{Advertising, Public Relations and some discursive appropriations. The case of Banco Itaú}

\author{
Sandra Ferreira de LIMA $^{1}$ \\ Gisela M. Pereira GONÇALVES ${ }^{2}$
}

\section{Resumo}

Este artigo apresenta como principal objetivo analisar as mudanças ocorridas nas estratégias discursivas publicitárias do Banco Itaú, ao longo das últimas quatro décadas, e a interdiscursividade da publicidade com as relações públicas na constituição de uma nova ordem do discurso da marca no Século XXI. Acredita-se que as mudanças ocorridas no comportamento do consumidor, provocadas pelas constantes mudanças econômicas e culturais, tanto na forma de consumir informação quanto de produzir conteúdo, possam ter enfraquecido o discurso publicitário, que precisou buscar nas relações públicas os conceitos necessários para reformular suas mensagens.

Palavras Chaves: Publicidade. Relações Publicas. Interdiscurso. Banco Itaú.

\begin{abstract}
This article presents as objective to analyze the changes occurred in the advertising strategies of Banco Itaú over the last four decades and the interdiscursivity of the publicity with public relations in the constitution of a new order of the discourse of the brand in the 21 st Century. The belief is that the changes in consumer behavior caused by constant economic and cultural changes, both in the way information is consumed and content produced, may have weakened the advertising discourse, which had to seek in public relations the concepts necessary to reformulate its comunication.
\end{abstract}

Keywords: Advertising. Public Relations. Interdiscourse. Banco Itaú.

1 Doutoranda em Ciências da Comunicação pela Universidade da Beira Interior. E-mail: sandrarrpp@gmail.com

${ }^{2}$ Professora e intergante do Labcom na Universidade da Beira Inteiror. Doutora em Ciências da Comunicação pela Universidade da Beira Interior. E-mail: gisela.ubi@gmail.com 


\section{Introdução}

O universo da comunicação mercadológica vem tendo que se adaptar de forma rápida e constante as mudanças ocorridas no comportamento dos consumidores e dos cidadãos ao redor do mundo, provocada durante décadas por mudanças climáticas que tiveram como consequência inúmeras tragédias naturais; também por problemas econômicos e sociais, gerados por guerras, atentados terroristas, e fuga em massa de pessoas de seu próprio país; além das constantes crises econômicas ao redor do mundo e tanto outros problemas mundiais e locais.

A publicidade que durante longos anos que se valeu do discurso do status, da diferenciação, do "bem estar", entre outros conceitos oriundos destes, entrou numa fase de descrédito provocada pela saturação das suas mensagens nos média de massa. Além disso, com o advento da internet, que possibilitou ao cidadão comum acessar uma enorme gama de informações, de estar conectado com um grande número de pessoas simultaneamente, e de produzir conteúdo interferindo cada vez mais na vida social, a publicidade viu o seu discurso se esvaziar.

Desta forma, considerando os novos desafios impostos pelas constantes mudanças no comportamento do consumidor, e o seu emponderamento crescente diante das novas tecnologias da informação, como as marcas tem ampliado suas estratégias discursivas para atender as exigências desse novo target? O objetivo deste artigo, portanto, é apresentar uma breve trajetória sobre a mudança das estratégias discursivas utilizadas pela publicidade, para gerar relacionamento do target com as marcas, analisando o caso do Banco Itaú S/A.

\section{Publicidade em tempos de crise ou tempos de crise para a publicidade?}

A publicidade esteve presente entre os ocidentais desde os primórdios da sua civilização. De acordo com Muniz (2004) os primeiros vestígios da atividade foram encontrados nos destroços de Pompeia, e se destinavam a divulgar combates de gladiadores, e também as diversas casas de banho existentes na cidade. Mas foi a parti do advento da imprensa, e depois com a revolução industrial, que exigia a geração cada 


\section{temática}

vez maior de consumo dos produtos, tornando necessário conquistar novos consumidores e impulsionar as vendas entre os consumidores habituais, que nasceu o marketing. E, o capitalismo sempre ávido na busca por clientes para aumentar a produção, para vender mais e para gerar mais lucro, percebe que a publicidade ligada ao marketing, com seu discurso persuasivo, possui maior capacidade de atrair os consumidores para determinados produtos ou serviços deixando-os mais desejáveis, tornando-a mais atrativa aos empresários. Já em 1978, conforme Kotler\& Mindak(1978, p.15) No final do século XIX, com o desenvolvimento dos mercados nacionais e da comunicação de massa, os fabricantes começaram a reconhecer o valor da publicidade como um complemento para suas atividades de força de vendas. Inegavelmente, a sua força residia na capacidade do seu discurso, e dos seus enunciados em persuadir consumidores a agir de determinada maneira. Para Nery(2005, p.13) o discurso publicitário se estruturou na busca por atender à reivindicação básica do ser humano: “a sensação de bem-estar”, e para isso constituiu-se muito mais além das palavras e imagens, tomando como base formas de representação social, transformando o objeto em signo, promovendo uma "relação imaginária entre o sujeito e a completude que ele esperava obter pelo valor de uso da mercadoria".

Pinto (1997, p.9) considera que a publicidade foi uma das linguagens persuasivas mais ativas e eficazes da contemporaneidade, por se utilizar de processos psicológicos, ideológicos e simbólicos para produzir sentido em suas mensagens, envolvendo o consumidor em uma "complexa teia feita de significado simbólico, que ajuda este último a digerir e a interessar-se pelos objectos em constante aparição". Ela observa, ainda, que a publicidade atuou sistematicamente numa dimensão conotativa e simbólica, explorando simultaneamente os valores intrínsecos e extrínsecos atribuídos ao produto, de modo a fazer com que o target ao qual se dirigia a mensagem se projetasse e se identificasse com o anuncio, ativando seu mundo imaginário, tomando como base a sua cultura.

Portanto, numa era de superprodução e consumismo, em que os produtos foram se tornando cada vez mais similares e o seu valor de uso já não se mostrava o principal atrativo para os consumidores, e que o valor simbólico se tornou o diferencial entre produtos e serviços perante o público alvo, a publicidade investida de um profundo conhecimento sobre seus consumidores, se tornou a ferramenta mais eficaz na 
construção de símbolos que refletiam "o mais fielmente possível esse conjunto de crenças, atitudes, ilusões dominantes numa determinada cultura, a que poderíamos chamar de imaginário coletivo"(PINTO, 1997,p.36).

Mas já nas últimas décadas do Século XX a publicidade dá sinais de fraqueza, e começa a ver seu discurso desacreditado e sua força de persuasão diminuída entre os consumidores. Kotler\&Keller (2014) observam que a década de 1990 marca um declínio da publicidade e um crescimento acentuado da promoção de vendas, somando mais de $30 \%$ à participação de $40 \%$ anterior que a promoção já possuía no orçamento combinado.

Para Ries \&Ries (2002, p. 26), a medida que o volume da publicidade cresceu, o impacto das suas mensagens diminuiu: "Quanto mais publicidade temos em determinado médium, menos efectivo se torna cada anúncio individualmente". Mas além saturação das mensagens publicitárias ao que o público foi exposto, o acesso a novas tecnologias da informação, o próprio acesso a informação, e a possibilidade de expressar suas opiniões e reivindicações de forma pública, principalmente com o advento das redes sociais, fez com que esse mesmo público se tornasse mais exigente, mais disperso, menos disposto a receber mensagens com as quais não se identificasse, com a qual não dialogasse, ou que não se coadunasse com seus valores. Para Tarsitano (2008) a publicidade vive um novo tempo, em que precisa deixar para trás hábitos que não combinam mais com os resultados financeiros buscados pelas empresas. Segundo ele o tempo dos prêmios já passou.

No momento em que o dinheiro é escasso, a concorrência acirrada, e o consumidor está cada vez mais exigente, o cliente está em busca de garantir sua participação no mercado, volume de vendas e neutralização da concorrência. O discurso da publicidade de "bem estar" e "modernidade" que funcionou bem durante a década de 1960, assim como a ideia da vida social como uma concorrência entre os indivíduos, implícita no apelo ao status, também deixou de funcionar (ROCHA, 2004). Tarsitano (2008), por sua vez, acredita que mesmo que as mudanças ocorridas no modo de se fazer e pensar publicidade até o início do Século XXI tenham se renovado, tanto em função do uso das novas tecnologias quanto no modo de condução dos processos produtivos, isso não foi suficiente para resolver o problema da falta de credibilidade e descrédito junto à opinião pública. 


\section{temática}

Portanto, esse conjunto de fatores mudaram o comportamento do consumidor, que passou a buscar informações, conselhos e recomendações em outras fontes mais confiáveis para ele, como amigos, vizinhos, pessoas da família, e também na imprensa. Mesmo não confiando em tudo que dizia, a imprensa também se constituiu como referência e fonte de informações para a tomada de decisão e formação da opinião para boa parte dos consumidores, durante várias décadas. Isso porque, conforme reflete Meditsch(1997), a notícia na imprensa sempre foi apresentada a audiência como sendo a realidade, e mesmo não se conhecendo concretamente os efeitos do jornalismo no público, era inegável a sua força na disseminação da informação e sua capacidade de formar opinião.

É diante deste contexto, que a publicidade precisou se reinventar: buscar novas estratégias, incorporar novas práticas, se reformular e se apropriar de outros discursos mais eficazes para atender seus novos consumidores, tentando assim garantir seu espaço junto ao marketing, já que o discurso, e as práticas, das relações públicas voltam a ganhar força no mix da comunicação mercadológica. Vale lembrar que do Mix fazem parte não só a publicidade, mas relações públicas, merchandising, promoção de vendas, ou qualquer outra ferramenta de comunicação que possa ser utilizada com fins mercadológicos.

\section{Relações Públicas}

Relações públicas nasce em uma época de grande efervescência da política sindical americana, pela necessidade tanto de sindicatos quanto de patrões de criar estratégias de mobilização da opinião pública em favor da sua causa. De acordo com PINHO (2008, p.32), o contexto histórico da sentença "O público que se dane", proferida por William Vanderbilt, empresário do ramo de estradas de ferro, revela a necessidade eminente das relações públicas, diante de uma sociedade civil organizada, permeada pelas lutas da classe trabalhadora, e de empresas que desejam trazer a opinião pública para o seu lado. Todavia, foi em 1903 que as relações públicas despontam no cenário americano pelas mãos, ou melhor dizendo, pelas palavras proferidas por Ivy Lee, jornalista e publicitário, que montou a primeira versão de uma assessoria de imprensa, que enviava aos veículos de imprensa press-releases com 
notícias sobre seus assessorados. Mas, é com Edward Bernays que as relações públicas sofreram uma reviravolta em suas atividades, ampliando seu escopo de atuação, usando fortemente técnicas propagandísticas (com base na psicologia), indo além da divulgação de notícias pela imprensa para atingir os objetivos dos clientes. “(...) A assessoria de imprensa não tinha particular destaque nos processos de formação de opinião de Bernays" (RIBEIRO, 2013, p.100).

Porém, se o primórdio da atividade não pode ser considerado um período propriamente do qual as relações públicas possam se orgulhar, é partir daí que sua trajetória apresentou desdobramentos conceituais e profissionais diferentes e mais abrangentes, indo além da divulgação de fatos referentes às empresas/instituições, com o objetivo de obter aprovação da opinião pública. O que ocorreu é que relações públicas ampliou seu campo de trabalho, atuando de forma estratégica, na busca pelo diálogo e pela compatibilização de interesses entre uma organização e seus públicos; e de maneira tática, a diagnosticar o relacionamento das organizações com seus públicos, de propor políticas e estratégias de relacionamento, de implementar programas e instrumentos que assegurassem a interação das entidades com seus públicos, de realizar pesquisas de opinião ${ }^{3}$ e imagem, de realizar planejamento da comunicação institucional e programas de comunicação estratégica, além de usar a divulgação de fatos e acontecimentos de interesse público ocorridos na organização, como forma de manter o público informado, favorecendo o diálogo entre ambas as partes, indo mais além da atividade de assessoria de imprensa.

Contudo, se a propaganda por sua vez, formulava mensagens de construção ideológica, penetrando nas consciências dos consumidores, construindo "atitudes, crenças e desejos mais profundos nos sujeitos, correntes de valores subconscientes, a que muitas vezes nem mesmo os próprios indivíduos têm acesso" (PINTO, 1997, p.35), mostrou-se também ineficaz quanto a gerar credibilidade para as organizações perante os seus públicos. Relações Públicas, por sua vez, se desenvolveu tomando como base o discurso do relacionamento, da interação, da busca do entendimento e do diálogo entre as organizações e seus públicos como condição básica para a construção de uma boa

\footnotetext{
3 Disponível em: http://www.abrpsaopaulo.com.br/guiabrasileiro/legislacao/federal/ parlamentonacional.htm
} 
reputação e credibilidade, e se não obteve a mesma popularidade e projeção da publicidade durante o "boom" do mercado de consumo, ainda assim, conseguiu manter seu espaço no ambiente corporativo. Para Ries\&Ries (2002) a publicidade, sozinha, nunca dispôs de credibilidade suficiente para construir reputação, considerando que publicidade é aquilo que o produto/empresa falam sobre si; enquanto relações públicas é aquilo que os outros falam sobre si(produto/empresa).

Quando analisou os quatro modelos de relações públicas, Gonçalves (2010) observou que a perspectiva da comunicação simétrica bidirecional, proposta por James Grunnig, representou ainda um avanço na maneira de se pensar relações públicas, já que pressupunha a condução de uma compreensão mútua entre as partes, posto que neste modelo existia a garantia "de um intercâmbio de informação pleno que conduza ao equilíbrio duradouro entre a uma organização e seus públicos” (GONÇALVES, 2010, p.29). Essa teoria, produziu uma nova ordem do discurso nas relações públicas, inserindo principalmente o conceito da transparência, visto que pensa a organização como um sistema aberto que emite "outputs para o ambiente e tem de se reajustar continuamente (retroacção ou feedback), para acompanhar o ritmo de desenvolvimento tecnológico, a evolução do mercado e as mudanças sociais, culturais e até políticas" ocorridas na sociedade (GONÇALVES, 2005, p. 407) Esse conceito, portanto, acaba por se tornar um referencial profícuo para amalgamar o discurso da transparência ao da responsabilidade social.

O modelo simétrico de relações públicas de James Grunig pode ser o ponto de partida para este estudo sobre a responsabilidade social das empresas modernas. Em Excellence in Public Relations and communication management, Grunig amadurece a sua teoria simétrica bidireccional enquanto teoria normativa das relações públicas, o único modelo para atingir a comunicação excelente.

Assim como Ries\&Ries (2002), acredita-se que relações públicas sempre exerceu papel fundamental na construção de marcas fortes, já que isso não é possível de acontecer se não houver credibilidade institucional (Wilcox, 2009). Uma empresa só consegue adquirir boa reputação perante o mercado e seu universo de públicos a medida que consegue criar e desenvolver relacionamentos fortes e duradouros com esses públicos, e a obsolescência da Publicidade colocou em evidência novamente as relações 


\section{temática}

públicas, já que no momento atual, a ordem do discurso na comunicação mercadológica parece ser "relacionamento" e "responsabilidade social".

Como observa Ries (2002, p.77) o problema da credibilidade com relação ao discurso da publicidade se tornou algo tão sério, que a mesma pode provocar efeito contrário do que é dito no público-alvo: "em algumas situações, esta provocação do oposto é tão poderosa que a publicidade pode, realmente, fazer mais mal do que bem ao anunciante". Essa realidade fica ainda mais latente com o surgimento da internet, conforme observa Domingues (2013) quando avalia que o ciberespaço se configurou a partir dos princípios da interação e da colaboração.

É nesse contexto que as atividades de relações públicas, permeadas pelo discurso do relacionamento e do diálogo que as organizações devem manter com seus públicos, voltam a tomar força, e a influenciar na ordem do discurso publicitário.

\section{O discurso do relacionamento e da responsabilidade social: o caso do Banco Itaú}

O propósito central desta análise é compreender como as estratégias discursivas da publicidade vem sem reformulando, tomando por meio a observação das suas estruturas discursivas e suas intersecções com o discurso das relações públicas, ao longo das últimas quatro décadas. Para atingir o objetivo proposto será utilizada a Análise do Discurso Francesa posto que seu interesse versa sobre como os discursos se constroem, como são distribuídos na sociedade, como falam sobre os sujeitos e sua história, e sobre as suas condições de produção, além de buscar compreender quais os sentidos que os discursos podem assumir sem deixar de considerar o contexto e a ideologia no qual o sujeito que fala está inserido.

$\mathrm{O}$ ponto de partida da análise tomou como fundamento o pensamento de Foucault (2008), de que os discursos possuem um suporte histórico e institucional que permitem ou proíbem um sujeito fazer uso de enunciados de determinado campo discursivo, e desta forma partiu-se de um estudo diacrônico das suas formações discursivas, com foco específico na propaganda institucional, tendo em vista que a diacronia não se trata de um processo histórico, mas da abordagem de uma sucessão de fatos de forma cronológica. O período determinado para o estudo não foi escolhido de forma aleatória, muito pelo contrário, foram durante essas quatro décadas em que 
ocorreram as grandes transformações tecnológicas, sociais e midiáticas, que influenciaram substancialmente uma mudança de comportamento do consumidor.

A partir do Recorte Diacrônico (o já dito em momentos diferentes) é possível fazer um desenho da malha discursiva do tema escolhido para estudo. O Recorte Diacrônico irá nos levar ao interdiscurso compreendido como o que já foi dito anteriormente sobre determinado assunto e está esquecido. Quando o analista organiza seu Recorte Diacrônico irá estabelecer um corpus determinado, em um período de tempo (que pode até abarcar décadas ou séculos) e um elenco de materiais(...). O analista não fará uma coletânea infinita, mas pinçará, por meio da identificação de regularidades discursivas, as formações discursivas presentes. (MOURA, 2009, p.66)

Sendo assim, o objeto empírico selecionado como exemplo foi a marca ITAU, já que o banco é anunciante durante o período determinado para este estudo, e tornaria possível observar as transformações ocorridas no discurso da publicidade da marca ao longo dessa trajetória. O corpus se constituiu pelo conjunto de slogans utilizados nas campanhas institucionais da marca, durante as últimas quatro décadas (1980, 1990, 2000 e 2010), considerando que a amostra seria representativa da formação discursiva constituinte em cada uma dessas décadas, tendo em vista que o conceito da sua produção publicitária reflete a filosofia e ideologia da marca com relação aos seus consumidores. O slogan apresenta uma forma concisa, de fácil assimilação e que resume o diferencial do produto e/ou da empresa, tendo como objetivos gerar no consumidor adesão, identificação e lembrança, levando-o a ação. O slogan é usado de forma mais perene, diferente da assinatura

Para Orlandi (2001) a formação discursiva é a base da análise do discurso, pois é a partir dela que se pode compreender o processo de produção de sentidos e estabelecer regularidades no funcionamento do discurso. “As formações discursivas podem ser vistas como regionalizações do interdiscurso, configurações específicas dos discursos em suas relações. O Interdiscurso disponibiliza dizeres, determinando, pelo já dito, aquilo que se constitui uma formação discursiva em relação a outra". (ORLANDI,2001, p.44)

Considerando, então, que a Análise do Discurso visa a compreensão sobre o funcionamento do discurso e como a linguagem produz sentido, o seu percurso analítico se inicia pelo sentido textual, da língua, ou seja, pelas frases, enunciados, contexto 
imediato, para seguir em busca do sentido ideológico, da história, do social, do contexto amplo (FONSECA, 2014). Esse processo, que para Orlandi (2001) se constitui na passagem do objeto simbólico para o objeto discursivo, é momento em que o pesquisador realiza uma análise da materialidade linguística que tem como princípio identificar: "o como se diz, o quem diz, em que circunstâncias etc. Isto é, naquilo que se mostra em sua sintaxe e enquanto processo de enunciação), fornecendo pistas para compreendermos o modo como o discurso que pesquisamos se textualiza (ORLANDI, 2001, P.65)

Nesta investigação, os textos que fazem parte do corpus, sofreram então a primeira análise textual, em que foi necessário fazer uma apreensão dos elementos linguísticos que se encontravam nos enunciados analisados, para que se pudesse perceber até que ponto palavras e expressões estivessem ali contribuindo para a produção de sentido, materializando discurso e discursos, revelando ideologia e ideologias (FONSECA, 2014, p.382). No segundo momento, partindo desta primeira fase em que foram analisadas as propriedades discursivas do texto tais como: sujeitos, espaço, tempo, tema, circunstâncias, elementos linguísticos etc, obtivemos então um objeto discursivo, que conforme Fonseca (2014, p.385) se trata do resultado da produção de sentidos daquilo que é dito pelo sujeito e que se insere numa formação discursiva dada, que por sua vez se insere numa formação ideológica. O objeto discursivo é também afetado por diferentes memórias discursivas, em que começa a se perceber o modo de funcionamento do discurso, e que será possível se detectar a sua relação com as formações discursivas. A próxima fase então se constituiu na passagem do objeto discursivo para o processo discursivo, onde se buscou as relações das formações discursivas e sua relação com a ideologia, o que nos permitiu compreender o que se constituiu como o dizer dos objetos de nossa análise.

\section{Leitura e análise do caso - Banco Itaú}

O Banco Itaú tem origem na fusão do Banco Federal de Crédito com o Banco Itaú, ligado a empresários mineiros, entre os anos de 1964 e 1965. Surgia assim o Banco Federal Itaú que começou a funcionar com uma rede de 112 agências, espalhadas por seis estados brasileiros, ocupando assim a $16^{\mathrm{a}}$. Posição no ranking dos maiores bancos 
do país. ${ }^{4}$ Em 1966, com a lei da reforma bancária, o Banco Federal Itaú foi o pioneiro a se tornar um banco de investimentos no país, e em 1969, com uma nova fusão realizada com o Banco da América S.A., o novo Banco Itaú América S.A. passou a contar com uma rede de 274 agências distribuídas por oito estados brasileiros. A década de 1970 representou um período de crescimento rápido para o banco, que realizou novas fusões, mas principalmente revitalizou sua marca se transformando novamente sua Razão Social e nome fantasia para Banco Itaú S/A. Ao final dessa década, estabeleceu seu approach evidenciando sua prioridade a tecnologia de ponta, e expressando o conceito de Banco Eletrônico, que foi trabalhada durante toda a década de 1980. Na década de 1990, seguindo a tendência de modernização do banco, a comunicação visual do ITAÚ foi totalmente reformulada, desde a criação de uma nova marca até a reorientação da programação visual de todo material promocional do banco, com ênfase no conceito de futuro, já que eram as expectativas para o novo milênio, o advento das novas tecnologias, que provocavam uma mudança o comportamento dos consumidores, que se tornavam mais atentos aos problemas sociais e as mudanças climáticas globais e locais.

Na década de 2000, o Itaú mudou o foco da sua comunicação. Pelas mãos da agência África, reformulou seu conceito, criando uma campanha institucional que tinha como objetivo falar diretamente com cada perfil de consumidor, ressaltando que apesar de ter sido feito para todos, respeitava culturas e perfis diferentes ${ }^{5}$, e para isso "regionalizou" a comunicação: em Porto Alegre utilizou o título: "Guris e gurias. O Itaú foi feito para vocês", já no Rio de Janeiro, se utilizou do título de duas músicas famosas cujos referentes remetem aos jovens do estado: "Garota de Ipanema e Meninos do Rio. O Itaú foi feito para vocês", em Salvador utilizaram o tratamento bem baiano: "Meu rei. O Itaú foi feito para você". A partir da década de 2010, o Itaú passa a investir com força em ações de responsabilidade social, e lança uma série de campanhas de cunho social, tais como: "Isso muda o mundo", "Cada momento conta", "Leia para uma criança", "Carta aos netos". Os slogans: Feito para você. (2010); Isso munda o mundo (2010); Feito pra Você (2006); Itaú: 60 Anos Sendo Feito para Você. (2005); Itaú. Feito

\footnotetext{
${ }^{4}$ Fonte: http://mundodasmarcas.blogspot.com.br/2006/07/ita-feito-para-voc.html

${ }^{5}$ Fonte: http://mundodasmarcas.blogspot.com.br/2006/07/ita-feito-para-voc.html
} 
para você. (2001); Itaú: pronto para o futuro. (1995); Itaú: todo dia um banco melhor para você. (1992); O Itaú está onde você precisa. (1988).

\section{Década de 1980}

A década de 1980 apresenta uma reviravolta no mundo ocidental. Acontecimentos importantes marcam a vida da população mundial e do brasileiro. No Brasil, com culminância da abertura política e fim dos governos militares, com desenvolvimento das novas tecnologias, com uma maior possibilidade de acesso às informações, além das constantes crises econômicas que se apresentaram neste período, acompanhou-se uma mudança significativa no comportamento da população, que começava a se tornar mais atenta, mais cautelosa no consumir. $\mathrm{O}$ desenvolvimento tecnológico que proporcionou mudanças na vida cotidiana do brasileiro e consumidor, também o fez na indústria, que viu sua capacidade de produção ampliada e precisava incentivar o consumo.

Acompanhando as mudanças ocorridas na década, o Itaú investe no conceito de modernidade e agilidade, já que é nesta época que implanta o Banco Eletrônico, e amplia o número de agências distribuídas pelo país. O slogan: O Itaú está onde você precisa, reflete esse movimento do banco. $\mathrm{O}$ enunciado sugere que onde quer que o cliente vá o banco estará lá para atendê-lo. Neste caso, o conceito trabalhado pelo banco ainda reflete o discurso publicitário do "bem estar", da comodidade e facilidade para a vida moderna.

\section{Década de 1990}

Esta década se inicia com grandes momentos de instabilidade econômica e política. O primeiro presidente eleito por voto direto, Fernando Collor de Mello, inicia seu governo confiscando poupanças, aplicações e parte do dinheiro das contas correntes no país. Momentos difíceis para a indústria, o comércio e principalmente para os bancos. Mas o seu governo durou pouco, e com o seu impeachment, assume o Vice Itamar Franco, que lança em 1994, junto com o então Ministro Fernando Henrique Cardoso, o plano real. Um plano que estabilizou economicamente o país e garantiu ao 
ministro a presidência da república por dois mandatos. Esta década também foi protagonista de um rápido desenvolvimento tecnológico e científico, além da valorização da cultura brasileira por meio do cinema, da música e do esporte. Entretanto, a chegada do novo milênio gerava ansiedade e dúvidas. Além do forte misticismo criado durante décadas entre a população mundial sobre um "possível fim do mundo", existia ainda a ameaça do Bug do milênio ${ }^{6}$. slogan: Itaú: todo dia um banco melhor para você assina uma série de campanhas destinadas a mostrar a evolução do banco com relação a melhoria dos serviços prestados aos clientes. O conceito ainda é o de promover o "bem estar" do cliente por meio da agilidade e facilidade que o banco pode proporcionar. Já no slogan, Itaú: pronto para o futuro, o banco quer deixar claro para o target o conceito de confiança e credibilidade. Estar pronto para o futuro naquela década pressupunha estar preparado para enfrentar os desafios que se apresentaria com o novo milênio, e isso incluía os desafios tecnológicos além das mudanças na vida cotidiana. O discurso gira em torno da eficiência, da agilidade e da competência para lidar com as dificuldades, e de gerar bem estar para seus clientes.

\section{Década de 2000}

A primeira década do Século XXI ficou marcada por inúmeros acontecimentos trágicos tanto para o homem quanto para o meio ambiente. Foram Tsunamis, guerras, quedas de aviões comerciais, ataques terroristas e desastres ecológicos. Fatos que tiveram uma enorme repercussão na maneira de pensar o mundo e o consumo, e de disseminar ideias e ideologias, com o advento da internet. Os governos passam a discutir mais fortemente acordos com foco no clima mundial, tendo em vista como as catastróficas ações humanas, afetaram substancialmente o equilíbrio ecológico mundial.

\footnotetext{
6 Bug do milênio poderia ser uma séria ameaça aos bancos e seus correntistas. "Como todas as datas eram representadas por somente 2 dígitos, os programas assumiam o "19" na frente para formar o ano completo. Assim, quando o calendário mudasse de 1999 para 2000 o computador iria entender que estava no ano de "19" + "00", ou seja, 1900.. Para além disso, temiam-se os efeitos que poderiam ser provocados no hardware pelo sistema BIOS, caso este reconhecesse apenas datas de dois dígitos. Caso as datas realmente voltassem" para 1900, clientes de bancos veriam suas aplicações dando juros negativos, credores passariam a ser devedores, e boletos de cobrança para o próximo mês seriam emitidos com cem anos de atraso..Fonte: Wikipedia.
} 


\section{temática}

Portanto, é nesta década que é possível observar mudanças substanciais no discurso da marca, por meio do seu slogan. Se anteriormente o foco era na tecnologia, na qualidade dos serviços e no atendimento, agora o foco passa a ser o cliente. O slogan Feito pra você reflete a preocupação do banco em falar diretamente o com cliente, personalizar. Como já apresentamos anteriormente, o conceito da personalização, gerou a adequação deste slogan em vários estados do Brasil. Quando a expressão que estereotipa o carioca: "Garota de Ipanema e Meninos do Rio. O Itaú foi feito para vocês", ou "Meu rei. O Itaú foi feito para você" o banco pretende demonstrar que é um banco bom para todos, mas que se preocupa com cada um, particularmente. $\mathrm{O}$ "feito pra você" reflete nitidamente a mudança do discurso da marca do bem estar para o diálogo, a preocupação com o indivíduo, com o diálogo, conceitos esses mais próximos do discurso das relações públicas.

\section{Década de 2010}

A década de 2010 reflete uma significativa mudança no comportamento dos cidadãos e consumidores, embaladas pela disseminação da internet, das redes sociais, e dos acontecimentos que embalaram as mudanças de comportamento no início do Século XXI. Os cidadãos ganharam força e visibilidade, e a ordem do discurso da propaganda institucional veiculada nos medias de massa, sem que pudesse haver contestação, tem de ficar para trás. Grupos de consumidores ou consumidores individuais, trocam informações pela rede, criam memes, convocam manifestações e provocam "viralizações". Ocorre por parte das organizações uma preocupação em falar com esses consumidores produtores de conteúdo (prosumers), e também com os cidadãos que militam na rede, propagando suas ideias e ideologias(netizens). Nenhuma empresa está livre da ação desses indivíduos em suas medias sociais.

A preocupação das marcas então é refletir os valores dos seus clientes, e quando não, tentar ao máximo gerar simpatia e harmonia com esses militantes das redes. É nesse contexto que o discurso da responsabilidade social ganha força na comunicação, $\mathrm{e}$ é abraçado pela publicidade. Apesar da manutenção do slogan: Feito pra você, é possível observar o crescimento das campanhas de cunho social e cultural realizadas pelo banco que utiliza como assinatura : "Isso muda o mundo", além de algumas 
temáticas que por vezes também funcionam como assinaturas : “Cada momento conta", "Leia para uma criança", "Carta aos netos"

No slogan "Isso muda o mundo" o Itaú abre um leque de possibilidade com o uso da palavra isso, posto que o termo pode se referir a qualquer coisa, e a produção de sentido do enunciado acontecerá de acordo com a ação apresentada na peça publicitária. Em "Cada momento conta", o banco apresenta uma série de casais que falam sobre como gostariam de estar mais com seus filhos, e como cada momento é importante". Fica subtendido que o banco está preocupado com a qualidade das relações entre pais e filhos, e que de alguma maneira pretende colaborar para melhorar esse tempo de convivência; com relação ao "Leia para uma criança" faz parte de uma campanha de cunho cultural em que o Itaú produziu uma série de livros infantis que foram distribuídos nas agências do banco, mesmo para quem não era cliente. Bastava se cadastrar no site e buscar nas agências credenciadas. O objetivo era incentivar os adultos a lerem para as crianças. Na campanha "Carta aos netos" o Itaú também utilizou a mesma estratégia discursiva, de preocupação com as relações humanas e familiares. $\mathrm{O}$ discurso do status, bem estar, facilidade, agilidade, entre outros já citados anteriormente, foi abandonado em detrimento do discurso da preocupação com o ser humano, foco da responsabilidade social.

\section{Considerações finais}

O caso do Banco Itaú pode ser uma amostra significativa para observação da mudança do discurso da publicidade com relação as marcas, tendo em vista que são anunciantes constantes, possuem um marketing atuante e constantemente antenado com as tendências de comportamento de consumo. Portanto, Se o elemento persuasivo continua a ser um forte elemento na argumentação publicitária, a utilização da técnica de projetar um consumidor ideal para afetar o consumidor real já não dá mais o "tom" das campanhas, e agora é o consumidor real quem vem ganhando espaço nas mensagens exibidas pela marca. $\mathrm{O}$ interdiscurso da publicidade com as relações se apresenta de forma clara na análise realizada, quando o banco assume o discurso da responsabilidade social como forma de aproximação com o seu target. 
Não restam dúvidas que as mudanças no comportamento do consumidor, e o seu empoderamento com o advento da internet e das medias sociais, tiveram papel preponderante na forma com que as marcas e a publicidade repensaram o conteúdo e o conceito de suas mensagens, e a tendência, como afirmam os estudiosos apresentados neste artigo é que o crescimento do discurso do relacionamento, do diálogo e das práticas das relações públicas apresentem uma tendência ao crescimento para as próximas décadas.

\section{Referências}

CREMADES, Javier. Trad. Edgar Charles. Micropoder. A força do cidadão na era digital. São Paulo: SENAC, 2009.

DOMINGUES, Izabela. Terrorismo de marca. Publicidade, discurso e consumerismo político na rede. Rio de Janeiro: Confraria do vento, 2013.

DOMINGUES, Izabela e PATRIOTA, K. Netizens e prosumers: novas mídias, cocriação e consumerismo político. Intercom - Sociedade Brasileira de Estudos Interdisciplinares da Comunicação XXXIII Congresso Brasileiro de Ciências da Comunicação - Caxias do Sul, RS - 2 a 6 de setembro de 2010.

FONSECA, Agripino José Freire da. Análise de Discurso: do objeto, do objetivo e do método. Breves considerações para principiantes. Revista Eletrônica Igarapé - No3, Maio de 2014.

GONÇALVES, Gisela. Introdução à Teoria das Relações Públicas. Porto: Porto Editora, 2010.

GONÇALVES, Gisela. Relações Públicas e responsabilidade pública: da visão sistémica à visão altruísta. In: Publicidade e Relações Públicas. ACTAS DO III SOPCOM, VI LUSOCOM e II IBÉRICO - Volume II.. Covilhã: UBI, 2005. Acessado em: http://www.bocc.ubi.pt/pag/goncalves-gisela-relacoes-publicas-responsabilidadepublica.pdf

KOTLER, Philip \& KELLER, Kevin L. Marketing Essencial: conceitos, estratégias e casos. São Paulo: Pearson Education, 2014.

KOTLER, Phillip \& MINDAK, William. Marketing and Public Relations. Should they be partners or rivals? AMERICAN MARKETING ASSOCIATION: Journal of Marketing, October 1978.

LUPETTI, Marcela. Planejamento de comunicação. São Paulo: Futura, 2003. 
MEDITSCH, Eduardo. O jornalismo é uma forma de conhecimento? http://www.bocc.ubi.pt/pag/meditsch-eduardo-jornalismo-conhecimento.pdf 1997.

MOURA, Dione Oliveira. O 'sincrônico', o 'diacrônico', o acontecimento e a errância de sentidos na Análise do Discurso jornalístico. Comunicação e Informação. v. 12, n.2: p. 63-73 - jul./dez. 2009

MUNIZ, Eloá. Publicidade e Propaganda. Origens Históricas. Canoas: Editora Ulbra, Caderno Universitário, $N^{\circ}$ 148, 2004. Acessado em: http://www.eloamuniz.com.br/arquivos/1188171156.pdf

NERY, Vanda Cunha Albieri. A construção do discurso publicitário na sociedade contemporânea. OPSIS - Revista do NIESC, Vol. 5, 2005.

PINHO, Júlio Afonso. O contexto histórico do nascimento das Relações Públicas. In: Moura, Claudia Peixoto(org.). História das relações públicas: fragmentos da memória de uma área. Porto Alegre : EDIPUCRS, 2008.

PINTO, Alexandra Guedes. Publicidade: um discurso da sedução. Porto: Porto Editora, 1997

ORLANDI, E. P. Análise de Discurso: princípios e procedimentos. Campinas, SP: Pontes, 2001.

FONSECA, Agripino José Freire da. Análise de Discurso: do objeto, do objetivo e do método. Breves considerações para principiantes. Revista Eletrônica Igarapé - No3, Maio de 2014

FOUCAULT, Michel. Arqueologia do Saber. Tradução de Luiz Felipe Baeta Neves,7ed. - Rio de Janeiro: Forense Universitária, 2008.

RIBEIRO, Vasco. O peso do pressrelease no processo de produção de notícias. Disponível em: http://www.bocc.ubi.pt/pag/ribeiro-vasco-2014-peso-do-pressrelease.pdf

. O campo e o triângulo operacional da assessoria de imprensa. In: Fronteiras e Fundamentos Conceptuais das Relações Públicas. COLEÇÃO: Relações Públicas e Comunicação Organizacional: dos fundamentos às práticas (vol. 1). (org.) Gisela Gonçalves \& Marcela Guimarães.

RIES, Al \& RIES, Laura. A queda da publicidade e a ascensão das relações públicas. Lisboa, Notícias Editoriais, 2002.

ROCHA, Maria Eduarda. A nova retórica do capital- publicidade brasileira entre o neoliberalismo e a democratização. Revista Comunicação, Mídia e Consumo. ESPM. V.1, No. 2, 2004. 
TARSITANO, Paulo Rogério. Publicidade brasileira: mudanças para continuar sendo forte. Revista Latino Americana de Ciências de La Comunicación. No8-9- EneroDeciembre 2008.

WILCOX, Denis L. \& CAMERON, Glen T. What is Public Relations? In: Public Relations. Stategies and Tatics. Boston: Pearson Education, 2009. 